\title{
Metamodel Approaches in Predicting the Seismic Response of Asymmetric Buildings
}

\author{
Philip Luke Karuthedath ${ }^{1}$, Deepak Kumar Sahoo ${ }^{2}$, Robin Davis P ${ }^{3}$, Pradip Sarkar ${ }^{2}$ \\ ${ }^{I}$ Department of Civil Engineering, Indian Institute of Technology Roorkee, India \\ ${ }^{2}$ Department of Civil Engineering, National Institute of Technology Rourkela, India \\ ${ }^{3}$ Department of Civil Engineering, National Institute of Technology Calicut, India
}

\begin{abstract}
:
Asymmetry formed as a result of the eccentricity between the positions of Centre of Mass and Centre of Stiffness can cause undesired torsional coupling and can weaken the seismic performance of buildings and structures. This dynamic response is further affected by the randomness in material, geometric and loading properties caused as a result of uncertainties in construction and functioning. Stochastic analyses methods such as Monte Carlo Simulation have been found to accurately characterize this randomness and uncertainty, but are computationally intensive as well as expensive. This necessitates the need for alternative analyses methods that are much simpler and can fairly represent the uncertainties while preserving the similarity in results. The present investigation considers the various metamodel approaches in non-statistical stochastic analyses methods in determining the seismic response of asymmetric buildings. The study observes the efficiency of the High Dimensional Model Representation (HDMR) approach in accurately predicting the free vibration response of a reinforced concrete frame with the least number of samplings points as well as computational effort as compared to other response surface methods. For further validation, a non-linear reliability analysis was carried out at HDMR sampling points to obtain the seismic fragility of the building considered, the results of which satisfied the fragility obtained using conventional methods.
\end{abstract}

Keywords: asymmetric buildings, HDMR, stochastic analysis, torsion, free-vibration, RSM

*Corresponding author: robin@ @itc.ac.in 


\section{Introduction}

Requirements of functionality and aesthetics in modern day high rise buildings have resulted in the design of complex and irregular shaped structures. This poses serious threat to the stability of buildings as irregularity leads to vulnerability when subjected to seismic loads. The irregular or asymmetric distribution of masses and stiffness in such buildings causes the Centre of Stiffness (CS) and Centre of Mass (CM) to be non-co-incident. Under seismic loads, torsional motion is induced in the structure in addition to lateral motion. This torsional-lateral coupling can cause increased deformation in the edges of these asymmetric buildings which can result in their sudden failure. Variation in the magnitude and intensity of the eccentricity (e) between CM and CS can further weaken the building. Being properly able to understand or predict the response of such structures subjected to high intense disastrous loading can assist the designers to prevent them from collapse.

In a real world scenario, the inevitability of uncertainty in building practices such as construction, maintenance and structural functioning makes it impossible to conclusively arrive upon the structural behavior under severe dynamic loading conditions like earthquakes, blast, tsunamis and hurricanes [1]. This uncertainty can occur anywhere in the building environment such as geometric properties, material properties or loading conditions. However previous studies [2] have shown the effectiveness of probabilistic analyses techniques and stochastic approaches to predict the response almost accurately. The stochastic approaches of analyses take into consideration, the uncertainty and randomness involved in various structural parameters. Statistical approaches (SA) in stochastic method involves Monte Carlo Simulation (MCS) [3], Latin Hypercube Sampling (LHS) [4], Stratified Sampling [5] etc. While MCS is a very efficient and powerful technique, the number of simulations it demands is very high and is thus computationally intense, time consuming and expensive [6]. And the success of LHS and Stratified Sampling depends on the sampling density.

Non-statistical approaches (NSA) of stochastic techniques were found to be a suitable alternative wherein the response of a structure is determined at selected sampling points that takes into consideration the randomness in the uncertainty parameter. Evaluation of the response gives a functional relationship between the input variables (uncertain parameters) and the output (response) [2]. This functional relationship is termed as the 'metamodel'. The metamodel basically 
is an approximation of the input data where the response is obtained using them in a closed-form function thus requiring less computational effort. Response surface Methods (RSM), the most common method of metamodel formulation in which the response surface forms the metamodel, has the most critical step as selection of the fewest possible input members; or in other words, sampling. Various techniques for design of experiments (DOE) are available for this such as the Central Composite Design (CCD) [7], Box-Behnken Design (BBD) [8], and Full Factorial Design (FFD). Many of these techniques have been already used for various studies regarding structural reliability and fragility analyses [9]-[13].

Recently, High Dimensional Model Representation (HDMR) [14] based response surface methods has emerged as a much simpler tool for stochastic approach. The HDMR method formulates a metamodel between the structural parameters and the response, thereby replacing the complex, non-linear structural model to a simple mathematical relationship. The method has been recently applied to determine the structural properties [15] and seismic fragilities [16] of buildings, but the potential has not been fully explored yet.

The possibility of such a stochastic method to determine the dynamic response of a building as random as a 3-dimensional multi-storied building has a large scope. The inherent characteristic of an asymmetric system; its eccentricity; as a result of the highly random distribution in mass and/or stiffness is a significant parameter that affects its response. This paper majorly aims at investigating the free vibration response of asymmetric buildings with respect to the various response surface methodologies and the efficiency of the newly developed HDMR method as compared to other established methods. Reliability analyses to develop the fragility curves of building systems is carried out further to validate the efficiency of the HDMR technique in nonlinear structural response spectra.

\section{Metamodel Approaches using RSM}

The general representation of a metamodel which uses the response surface methodology is as in Eq. (1).

$$
y=f\left(x_{i}\right)
$$

where the output $y$ is the required response of the system and $x_{i}$ denotes the input. There is an error term $\varepsilon$ as well, which can be neglected in case of computer analyses [17]. So the equation is 
basically a polynomial function where the uncertainty and randomness in the determination of input variables (parameters) can cause an uncertainty or randomness in the output (response). The selection of the order of the polynomial function depends on the type and scale of the problem definition; a first order polynomial is generally used for a linear system whereas for systems with nonlinearity, higher order functions are selected [18].

For the present study, a second order quadratic polynomial function as proposed by [17] is selected; represented as in Eq. (2).

$$
y=\beta_{0}+\sum_{i=1}^{k} \beta_{i} x_{i}+\sum_{i=1}^{k} \beta_{i i} x_{i}^{2}+\sum_{i=1}^{k-1} \sum_{j=1}^{k} \beta_{i j} x_{i} x_{j}
$$

where, $\beta=$ unknown coefficients or constants; $k=$ total number of input variables.

Response surface methodology refers not simply to the use of a response surface as a multivariate function, but also to the process for determining the polynomial coefficients, $\beta$. Several design of experiment methods are available for that. They use different methods to arrive at a combination of the specified input variables, known as the sampling points. The number of sampling points depend upon the number of input variables and the design of experiment. The different design or sampling methods adopted in this work are CCD, BBD and Full Factorial Designs (FFD). Details on the DOE sampling methods, CCD, FFD and BBD can be found here [18].

Responses of the system corresponding to the sampling points are determined and by knowing both the input and output, the unknown coefficients of the polynomial function can be estimated. From that a metamodel is established between the system parameters and the response.

\section{Metamodel using HDMR}

Recent years have seen the development of approximate functions to represent the response of nonlinear systems, which otherwise is very tedious to calculate. One such analysis tool is the High Dimensional Model Representation (HDMR) metamodel approach, wherein complex and computationally expensive systems are reduced to a simple input-output relationship of variables consisting of their high dimensional behaviour. The order of the approximation of each variable starts from a constant and proceeds higher with independent as well as associative function. It is a very efficient formulation of the system response, if higher-order variable correlations are weak, 
allowing the physical model to be captured by the first few lower-order terms. The uncertainty analysis of the computationally burdensome system or model can then be well approximated by the use of Monte Carlo simulation of the corresponding reduced model, at a much lower computational cost without compromising the accuracy [16].

Consider a system having $\mathrm{N}$ input variables, represented in the vector form $x=\left\{x_{1}, x_{2}, \ldots x_{N}\right\}$ and let the response of the system be $f(x)$ The effect of the input variables on the output can be a hierarchical correlated function expansion as expressed in Eq. (3).

$$
f(x)=f_{0}+\sum_{i=1}^{N} f_{i}\left(x_{i}\right)+\sum_{1<i_{1}<i_{2}<N} f_{i_{1} i_{2}}\left(x_{i_{1}}, x_{i_{2}}\right)+\sum_{1<i_{1}<i_{2}<i_{3}<N} f_{i_{i} i_{2} i_{3}}\left(x_{i_{1}}, x_{i_{2}}, x_{i_{3}}\right)+\ldots \ldots+f_{i_{i} i_{2} \ldots \ldots i_{N}}\left(x_{i_{1}}, x_{i_{2}}, \ldots \ldots . . . x_{i_{N}}\right)
$$

where, ${ }^{f_{0}}$ is the constant obtained by the response $f(x)$ at a selected reference point (mean point), $f_{i}\left(x_{i}\right)$ is the first order term representing the individual contribution of the variable ${ }^{x_{i}}$ on the output, $f_{i_{1} i_{2}}$ is the second order term for the co-operative effects of the variables $x_{i_{1}}$ and $x_{i_{2}}$ on the output, $f_{i_{1} i_{2} \ldots i_{N}}\left(x_{i_{1}}, x_{i_{2}}, \ldots x_{i_{N}}\right)$ is the residual dependence of all the input variables that influence the output $f(x)$ . Determining each of the functions in the RHS of Eq. (3) and combining the similar terms together gives the HDMR metamodel to determine the required output/response of the system under consideration. Generally, the effect of higher order and cooperative relation between the variables are negligible/non-existant and the HDMR method can be satisfactorily expanded up to second order.

HDMR functions specified in Eq. (3) can be expanded using any of the two available methods, namely the analyses of variance (ANOVA) method or the cut-HDMR method. The former method is used to determine the contributions of the variance of individual component functions to the overall variance of the output. While in cut-HDMR method, a reference point (mean point, generally) is decided first and then the results are determined along the lines, planes, volumes etc., through and around this point. While the ANOVA method produces a good average value everywhere in the domain, the cut-HDMR method gives an exact result in a hyperplane passing through the reference point. For the present investigation, the cut-HDMR method is used.

The selection of the reference variable vector, $c=\left\{c_{1}, c_{2}, c_{3}, \ldots c_{N}\right\}$ for the cut-HDMR is very important especially in cases where only the lower order of the functions in Eq. (3) are considered 
(like in the present study). The said point is generally chosen at the mean points of all the random variables considered in the formulation, i.e. $c$ consists of the mean values of the input variable space. Analysis of the system is carried out relative to this reference point and the component functions in Eq. (3) are reduced as

$$
\begin{gathered}
f_{0}=f(c) \\
f_{i}\left(x_{i}\right)=f\left(x_{i}, c^{i}\right)-f_{0} \\
f_{i_{1} i_{2}}\left(x_{i_{1}}, x_{i_{2}}\right)=f\left(x_{i_{1}}, x_{i_{2}}, c^{i_{1} i_{2}}\right)-f_{i_{1}}\left(x_{i_{1}}\right)-f_{i_{2}}\left(x_{i_{2}}\right)-f_{0}
\end{gathered}
$$

In Eq. (5), $f\left(x_{i}, c^{i}\right)=f\left(c_{1}, c_{2}, \ldots, c_{i-1}, x_{i}, c_{i+1}, \ldots c_{N}\right)$, corresponds to the situation when all the random variables considered in the study, except for xi, are at their reference (mean) points. In a similar manner, the function $f\left(x_{i_{1}}, x_{i_{2}}, c_{i_{1}}, c_{i_{2}}\right)=f\left(c_{1}, c_{2}, \ldots c_{i_{1}-1}, x_{i_{1}}, c_{i_{1}+1}, \ldots c_{i_{2}-1}, x_{i_{2}}, c_{i_{2}+1}, \ldots, c_{N}\right)$ means that the random variables except $\left(x_{i_{1}}, x_{i_{2}}\right)$ are at their reference points. The $f_{0}$ term is evaluated as the response obtained when all the random variables are at their reference points, $c$. The higher order terms are evaluated as cuts in the input variable space around the reference point. Therefore, each first-order term $f_{i}\left(x_{i}\right)$ is evaluated along its variable axis througih the reference point. Each second-order term $f_{i_{1} i_{2}}\left(x_{i_{1}}, x_{i_{2}}\right)$ is evaluated in a plane defined by the binary set of input variables $\left(x_{i_{1}}, x_{i_{2}}\right)$ through the reference point, etc.. The lower order expansion functions are subtracted off to remove the dependency.

A three-point sampling is used in the current study for the development of HDMR metamodel. The sampling process using three-point sampling method for two $(n=2)$ random parameters, ${ }^{x_{1}}$ and ${ }^{x_{2}}$ can be explained with the help of Fig 1 . The horizontal and vertical axis represents the parameters ${ }^{x_{1}}$ and ${ }^{x_{2}}$ respectively. The sampling points to be considered for the input - output combinations are represented by grid points. There are five $(2 * n+1=2 * 2+1=5)$ grid points for the two parameters, ${ }^{x_{1}}$ and ${ }^{x_{2}}$. The center sampling point at $\left(x_{1}, x_{2}\right)$ is represented by mean values of parameter of ${ }^{x_{1}}$ and ${ }^{x_{2}}$. When a parameter ${ }^{x_{1}}$ is considered, two sampling points, $\left(x_{1 \mu}+x_{1 \sigma}, x_{2 \mu}\right)$ and $\left(x_{1 \mu}-x_{1 \sigma}, x_{2 \mu}\right)$ on either side of mean of ${ }^{x_{1}}$ shall also be considered. The output value at the three sampling points is the requirement of the method to solve the three constants of the metamodel function contribution involving ${ }^{x_{1}}$ alone. Similarly, there will three sampling 
points (with a common center point) to be considered for the random variable, ${ }_{2}^{x_{2}}$. When there are more number of random variables, the grid will have that many dimensions in space.

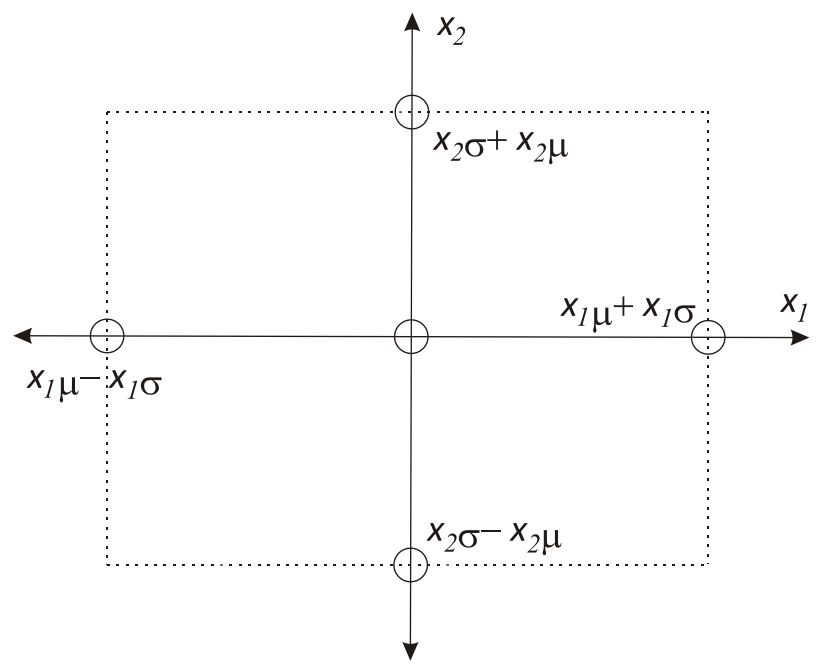

Figure 1. Schematic two dimensional representation of sampling in HDMR

\section{Free Vibration Analysis}

For a building which is asymmetric in mass, stiffness or strength, the basic parameter that influences their torsional behaviour under heavy and dynamic loads is their frequency ratio. It is the ratio between the uncoupled torsional frequency and uncoupled lateral frequency of the structure. Determination of frequency ratio for an asymmetric system is heavily influenced by the geometry and elastic properties of the system and thus the randomness in estimating these properties causes an uncertainty in calculating the frequency. Previous studies [19]-[22] have shown the depth with which the change in this parameter can affect the building deformation under seismic loads. In this investigation, stochastic analysis is carried out using metamodel based approaches (BBD, CCD, FFD, HDMR) to determine the uncoupled lateral frequency, hereafter referred as the natural frequency of an asymmetric system. In a similar manner, the torsional frequency can also be obtained, and thus the Uncoupled frequency ratio, but is omitted in the study because of space constraints. The accuracy of the results and the metamodel formed are verified using the MCS method.

\subsection{Structural Modeling and Description:}

For the present study, investigation is done on an RC bare frame having 4 storeys and 5 bays in both the plan directions as shown in Fig. 2. Typical storey height and bay width are taken as 3.2 
$\mathrm{m}$ and $5 \mathrm{~m}$ respectively. Yield strengths of the concrete and rebar are respectively taken as $25 \mathrm{MPa}$ and $415 \mathrm{MPa}$. The base of the building is assumed to be fixed. The design of the buildings is based on the Indian Standards of RC construction [23].

The modeling and analysis of the building is done using the OpenSees framework developed at the Pacific Earthquake Engineering Research (PEER) center [24]. A force-based nonlinear beamcolumn fiber element that considers the spread of plasticity along the element is used for modeling the beams and columns for the free vibration analysis. Formulation of the fiber-based element is explained in [25]. The core concrete is modeled by considering the effect of confinement due to the special reinforcement detailing in the beams and columns using the Kent and Park model [26] model. The cover concrete is modeled as unconfined concrete. Steel-reinforcing bars are modeled using uniaxial Giuffre-Menegotto-Pinto steel material model with isotropic strain hardening. More details about reinforcement modelings used in the present study can be found in [27].

Floors are modeled as rigid slabs and soil-structure interaction effects are considered to be insignificant. Structural damping (with 5\% damping ratio) is modeled using a Rayleigh- type damping and proportional to mass and initial-stiffness of structural elements.

Asymmetry is induced in the building by shifting the position of the CM by providing lumped masses at a distance equivalent to the required asymmetry (eccentricity), from the centre of gravity. The study considers only unidirectional asymmetry and it is assumed that the displaced position of CM is the same in each storey. In Fig 2(b), CG is the coincident position of the centre of gravity and centre of stiffness whereas CM is the position of Centre of Mass.

\subsection{Quantification of Uncertainties}

The significant parameters that affect the free vibration response of a building were studied and the uncertainty analysis was carried out by considering them as random variables. Studies on previous literature provided the distribution and randomness of these parameters. A total of 8 random variables were used for the study, the details of which are given in Table 1. For the eccentricity parameter, the considered uniform distribution is based on the code provisions of accidental eccentricity, which dictate that a minimum of 0.05 times the lateral dimension of the building is to be considered for eccentricity; and the study by Annigeri et al [19] where they observed that the maximum eccentricity to width ratio in any buildings will not exceed 0.35 times its lateral dimension. 


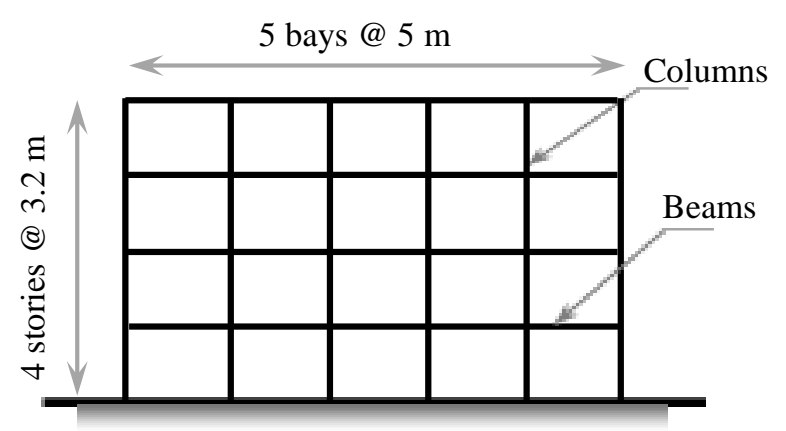

a) Plan

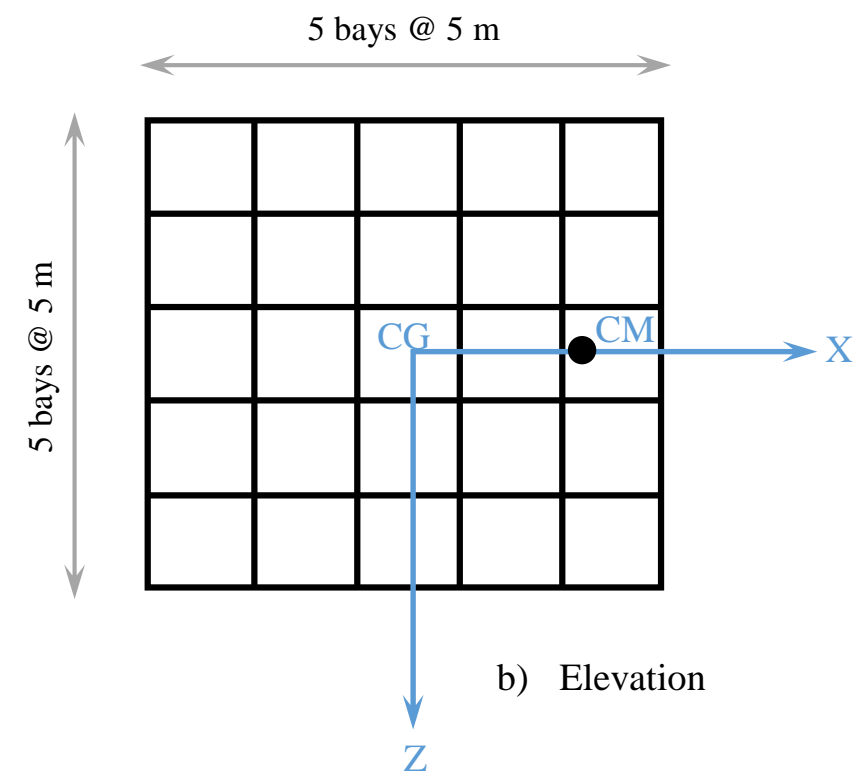

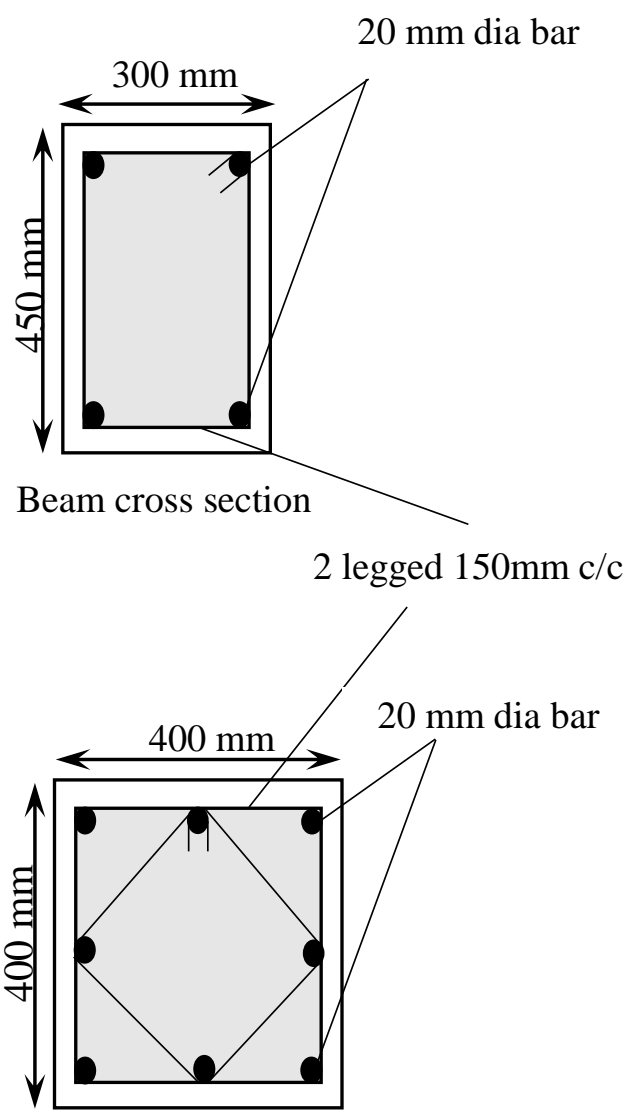

Column cross section

Figure 2. Geometry and Section Details of the example building

\subsection{Metamodel formulation using HDMR}

For the present investigation, the natural frequency of the asymmetric building model taken is considered as the response to be evaluated and a functional relationship is established between this response and the parameters (given in Table 1) influencing this response; which gives the required metamodel. To construct this metamodel, free vibration analysis of the building modelled is carried with selected sampling points as the building parameters. Three-point sampling method as mentioned (Fig 1) has been found sufficient for accurately representing the randomness in the parameters and the values at sampling points for all the 8 random variables considered are given in Table 2.

Table 1. Statistical Details of Random Variables 


\begin{tabular}{|c|c|c|c|c|c|}
\hline $\begin{array}{c}\text { Sl. } \\
\text { No }\end{array}$ & Propery & Mean & $\begin{array}{c}\text { COV } \\
(\%)\end{array}$ & $\begin{array}{c}\text { Probability } \\
\text { Distribution }\end{array}$ & Source \\
\hline 1 & $\begin{array}{c}\text { Modulus of Elasticity } \\
(\mathrm{Ec})\end{array}$ & $29000 \mathrm{E} 06 \mathrm{~N} / \mathrm{m}^{2}$ & 21 & Normal & {$[28]$} \\
\hline 2 & Live Load (wL) & $1.5 \mathrm{E} 06 \mathrm{kN} / \mathrm{m} 2$ & 10 & Normal & {$[29]$} \\
\hline 3 & Storey Height (h) & $3 \mathrm{~m}$ & 8 & Lognormal & {$[30]$} \\
\hline 4 & Beam Depth (Bd) & $0.45 \mathrm{~m}$ & 1.5 & Normal & {$[31]$} \\
\hline 5 & Beam Width (Bw) & $0.3 \mathrm{~m}$ & 3 & Normal & {$[31]$} \\
\hline 6 & Column Depth (Cd) & $0.4 \mathrm{~m}$ & 1.5 & Normal & {$[31]$} \\
\hline 7 & Column Width (Cw) & $0.4 \mathrm{~m}$ & 3 & Normal & {$[31]$} \\
\hline 8 & Eccentricity/Width (e) & 0.2 & 0.75 & Uniform & {$[19]$} \\
\hline
\end{tabular}

Table 2: Values of input variables obtained using three-point sampling

\begin{tabular}{|c|c|c|c|}
\hline Variable & $\mu-\sigma^{*}$ & $\mu$ & $\mu+\sigma$ \\
\hline$E c\left(\mathrm{~N} / \mathrm{m}^{2}\right) 10^{6}$ & 24650 & 29000 & 33350 \\
\hline$w_{L}\left(\mathrm{kN} / \mathrm{m}^{2}\right)$ & 1.35 & 1.5 & 1.65 \\
\hline$h(\mathrm{~m})$ & 2.76 & 3 & 3.24 \\
\hline$B_{d}(\mathrm{~m})$ & 0.44 & 0.44325 & 0.45675 \\
\hline$B_{w}(\mathrm{~m})$ & 0.291 & 0.3 & 0.309 \\
\hline$C_{d}(\mathrm{~m})$ & 0.394 & 0.4 & 0.406 \\
\hline$C_{w}(\mathrm{~m})$ & 0.388 & 0.4 & 0.412 \\
\hline$e$ & 0.05 & 0.2 & 0.35 \\
\hline
\end{tabular}

$* \mu$ and $\sigma$ are the mean and standard deviation of the random variables.

Expanding and simplifying the general form of HDMR (Eq. (3)) to represent the metamodel of the free vibration frequency response of an asymmetric building can be expressed as:

$$
\omega=f_{0}+f\left(E_{c}\right)+f\left(w_{L}\right)+f(h)+f\left(B_{d}\right)+f\left(B_{w}\right)+f\left(C_{d}\right)+f\left(C_{w}\right)+f(e)
$$


where $f\left(E_{c}\right), f\left(w_{L}\right), f(h), f\left(B_{d}\right), f\left(B_{w}\right), f\left(C_{d}\right), f\left(C_{w}\right)$ and $f(e)$ represents the second order polynomial function of the respective random variable as

$$
f(z)=a_{0}+a_{1} z+a_{2} z^{2}
$$

Higher order terms as well as associative terms have been observed to influence only slightly to the accuracy of the metamodel, while at the same time making the system computationally intensive and requiring more sampling points. Thus the authors felt the sufficiency of second order independent polynomials and three-point sampling method to accurately represent the influence of each random variable to the frequency response.

To obtain the coefficients ${ }^{a_{0}},{ }^{a_{1}}$ and ${ }^{a_{2}}$, calculation is done on three sampling points where all the other random variables except for the $z$, whose coefficients need to be determined are at their reference points. Once the coefficients of all the random variables are similarly obtained, they are grouped together to formulate the required HDMR metamodel,

Since for each random variable, 3 sampling points are taken; therefore for 8 variables, a total of $17(8 * 2+1)$ points are sampled, the input and frequency response of which are as shown in Table 3. The truncated values of coefficients obtained for each of the 8 variables by solving these equations are shown in Table 4.

Table 3. Sampling point combinations and their output using HDMR

\begin{tabular}{|c|c|c|c|c|c|c|c|c|c|c|}
\hline \multirow[b]{2}{*}{$\begin{array}{l}\text { Sl. } \\
\text { No }\end{array}$} & \multirow[b]{2}{*}{$\begin{array}{c}E_{c} \\
\left(\mathrm{~N} / \mathrm{m}^{2}\right) \\
\text { E06 }\end{array}$} & \multirow[b]{2}{*}{$\begin{array}{c}w_{L} \\
\left(\mathrm{~N} / \mathrm{m}^{2}\right) \\
\text { E03 }\end{array}$} & \multirow[b]{2}{*}{$\begin{array}{c}h \\
(\mathrm{~m})\end{array}$} & \multirow[b]{2}{*}{$B_{d}(\mathrm{~m})$} & \multirow[b]{2}{*}{$\begin{array}{l}B_{w} \\
(\mathrm{~m})\end{array}$} & \multirow[b]{2}{*}{$\begin{array}{l}C_{d} \\
(\mathrm{~m})\end{array}$} & \multirow[b]{2}{*}{$\begin{array}{l}C_{w} \\
\text { (m) }\end{array}$} & & \multicolumn{2}{|c|}{$\omega(\mathrm{Hz})$} \\
\hline & & & & & & & & & $\begin{array}{c}\text { At } \\
\text { sampling } \\
\text { points }\end{array}$ & $\begin{array}{c}\text { Predicted } \\
\text { using } \\
\text { HDMR }\end{array}$ \\
\hline 1 & 29000 & 1.5 & 3 & 0.45 & 0.3 & 0.4 & 0.4 & 0.2 & 2.609807 & 2.609807 \\
\hline 2 & 24650 & 1.5 & 3 & 0.45 & 0.3 & 0.4 & 0.4 & 0.2 & 2.422408 & 2.422408 \\
\hline 3 & 33350 & 1.5 & 3 & 0.45 & 0.3 & 0.4 & 0.4 & 0.2 & 2.800438 & 2.800438 \\
\hline 4 & 290000 & 1.3 & 3 & 0.45 & 0.3 & 0.4 & 0.4 & 0.2 & 2.614329 & 2.614329 \\
\hline 5 & 290000 & 1.65 & 3 & 0.45 & 0.3 & 0.4 & 0.4 & 0.2 & 2.605309 & 2.605309 \\
\hline
\end{tabular}




\begin{tabular}{|c|c|c|c|c|c|c|c|c|c|c|}
\hline 6 & 29000 & 1.5 & 2.76 & 0.45 & 0.3 & 0.4 & 0.4 & 0.2 & 2.911159 & 2.911159 \\
\hline 7 & 29000 & 1.5 & 3.24 & 0.45 & 0.3 & 0.4 & 0.4 & 0.2 & 2.357252 & 2.357252 \\
\hline 8 & 29000 & 1.5 & 3 & 0.4433 & 0.3 & 0.4 & 0.4 & 0.2 & 2.587254 & 2.587254 \\
\hline 9 & 29000 & 1.5 & 3 & 0.4567 & 0.3 & 0.4 & 0.4 & 0.2 & 2.631766 & 2.631766 \\
\hline 10 & 29000 & 1.5 & 3 & 0.45 & 0.291 & 0.4 & 0.4 & 0.2 & 2.605894 & 2.605894 \\
\hline 11 & 29000 & 1.5 & 3 & 0.45 & 0.309 & 0.4 & 0.4 & 0.2 & 2.613418 & 2.613418 \\
\hline 12 & 29000 & 1.5 & 3 & 0.45 & 0.3 & 0.394 & 0.4 & 0.2 & 2.585465 & 2.585465 \\
\hline 13 & 29000 & 1.5 & 3 & 0.45 & 0.3 & 0.406 & 0.4 & 0.2 & 2.633497 & 2.633497 \\
\hline 14 & 29000 & 1.5 & 3 & 0.45 & 0.3 & 0.4 & 0.388 & 0.2 & 2.598306 & 2.598306 \\
\hline 15 & 29000 & 1.5 & 3 & 0.45 & 0.3 & 0.4 & 0.412 & 0.2 & 2.620541 & 2.620541 \\
\hline 16 & 29000 & 1.5 & 3 & 0.45 & 0.3 & 0.4 & 0.4 & 0.05 & 2.650114 & 2.650114 \\
\hline 17 & 29000 & 1.5 & 3 & 0.45 & 0.3 & 0.4 & 0.4 & 0.35 & 2.525935 & 2.525935 \\
\hline
\end{tabular}

Grouping together the coefficients of the constansts and the variables, the metamodel to obtain the frequency response of an asymmetric building subjected to the influence of parameters of $E_{\mathcal{C}}, w_{L}$, $h, B_{d}, B_{w}, C_{d}, C_{w}$ and $e$ can be represented as

$$
\begin{aligned}
& \omega=1.801897+(3.85 \mathrm{E}-11) * E c+(8.536 E-23) * E c^{2}-(3.2 E-05) w_{L}+(5.17 E-10) w_{L}{ }^{2}+9.292 B_{d}-6.63 B_{d}{ }^{2} \\
& -3.696 h+0.4236 h^{2}+1.542 B_{w}-1.843 B_{w}{ }^{2}+11.252 C_{d}-9.062 C_{d}{ }^{2}+3.059 C_{w}-2.67 C_{w}{ }^{2}-0.027 e-0.968 e^{2}
\end{aligned}
$$

The accuracy of the HDMR metamodel obtained in the study is better represented using a graph between the free vibration analyses results and the original metamodel (Eq. (9)) values, calculated at the sampling points used. This graph is plotted in Fig 3 and it can be observed that there is absolutely no variation $\left(\mathrm{R}^{2}=1\right)$ between the analyses results and the values obtained from the metamodel.

Table 4. Coefficients of metamodel obtained using HDMR approach 


\begin{tabular}{|c|c|c|c|c|c|c|c|c|}
\hline & \multicolumn{7}{|c|}{ HDMR } \\
\hline Coefficients & $E_{c}$ & $w_{L}$ & $h$ & $B_{d}$ & $B_{w}$ & $C_{d}$ & $C_{w}$ & $e$ \\
\hline$a_{0}$ & -1.18831 & 0.0463 & 7.275 & -2.84 & -0.294 & -3.051 & -0.800 & 0.0441 \\
\hline$a_{l}$ & $3.85 \mathrm{E}-11$ & $\begin{array}{c}-3.2 \mathrm{E}- \\
05\end{array}$ & -3.696 & 9.292 & 1.542 & 11.252 & 3.059 & -0.027 \\
\hline$a_{2}$ & $8.536 \mathrm{E}-23$ & $\begin{array}{c}5.17 \mathrm{E}- \\
10\end{array}$ & 0.4236 & -6.63 & -1.873 & -9.062 & -2.67 & -0.968 \\
\hline
\end{tabular}

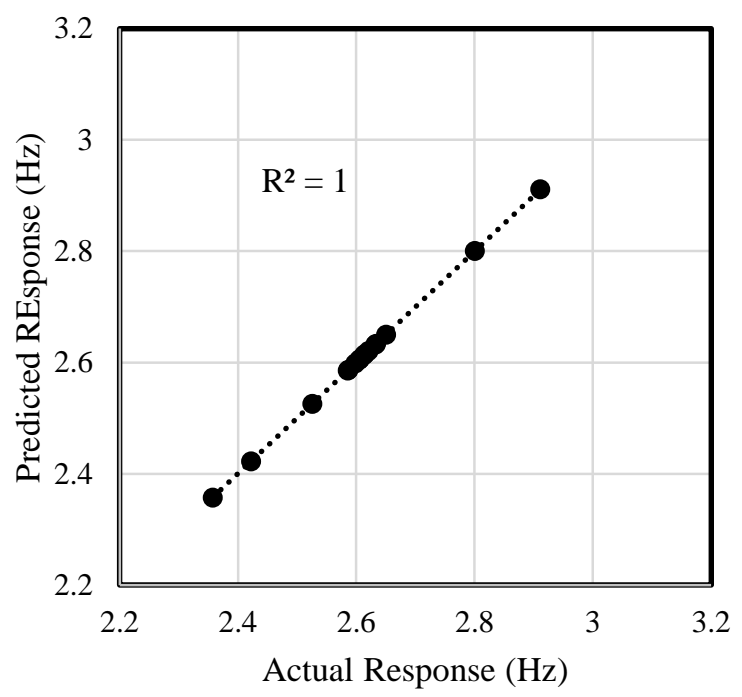

Figure 3. Comparison of Natural frequency with predicted response using HDMR metamodel

\subsection{Metamodel formualation using RSM}

The basics of metamodel formulation using response surface methods follow the same idea as that of HDMR. The general metamodel follows the same form as that of Eq. (3). Free vibration analyses are carried out at the sampling points and the results obtained are analyzed to obtain the coefficients for each random variable. The number and extent of sampling points used depends on the design of experiment under consideration. For the present study, BBD, FFD and CCD design of experiments are used. 
Unlike the HDMR method, where the coefficients for each variable was separately calculated from separate sampling points; here the response surface is generated using all the input variables and their response together at the sampling points. A single order polynomial is considered and the general representation of the metamodel for all the DOE used in the study for representing the natural frequency of the building is as given in Eq. (10).

$$
\omega=a_{0}+a_{1} z_{1}+a_{2} z_{2}+\ldots .+a_{8} z_{8}
$$

where $\left\{a_{1}, a_{2}, \ldots, a_{8}\right\}$ denotes the coefficients for each of the random variable in $\left\{z_{1}, z_{2}, \ldots, z_{8}\right\}$. The values taken for each of the random variable follow the same distribution as in Table 1. A MATLAB program was developed as to the cause of providing the sampling points from the input variables for each DOE. Since the number of sampling points involved for RSM methods are large, they are deliberately not tabulated in this paper. From the results of free vibration analysis at these sampling points, coefficients of the random variables are determined. The truncated values of coefficients for each of the DOE are given in Table 5. Grouping them together gives the appropriate metamodels of response surface methodologies.

To understand the accuracy of metamodels using RSM, graphs were plotted between the frequency from OpenSees analysis and the frequency calcualated using metamodoel, for each DOE and are given in Fig 4. It is observed that for the RSM methods, there is actually a variation between both the values $\left(\mathrm{R}^{2}<1\right)$ as opposed to the perfect unity in HDMR method. This can be attributed to the fact that the HDMR method involves the solution of simultaneous equations having number of variables equal to number of unknowns while in the other metamodels, the method is to minimize the error in order to calculate the coefficients.

Table 5. Coefficients for random variables for RSM based Design of Experiments

\begin{tabular}{|c|c|c|c|c|c|c|c|c|c|}
\hline \multirow{2}{*}{$\begin{array}{c}\text { Design of } \\
\text { Experiment }\end{array}$} & \multicolumn{10}{|c|}{ Coefficients } \\
\cline { 2 - 10 } & $a_{0}$ & $E_{c}$ & $w_{L}$ & $h$ & $B_{d}$ & $B_{w}$ & $C_{d}$ & $C_{w}$ & $e$ \\
\hline BBD & 1.354 & $4.35 \mathrm{E}-11$ & $-3 \mathrm{E}-05$ & -1.1525 & 3.325 & 0.421 & 3.779 & 1.110 & -0.401 \\
\hline CCD & 1.327 & $4.35 \mathrm{E}-11$ & $-3 \mathrm{E}-05$ & -1.147 & 3.324 & 0.420 & 3.997 & 0.931 & -0.421 \\
\hline FFD & 1.310 & $4.34 \mathrm{E}-11$ & $-3 \mathrm{E}-05$ & -1.141 & 3.310 & 0.423 & 3.0415 & 1.843 & -0.351 \\
\hline
\end{tabular}




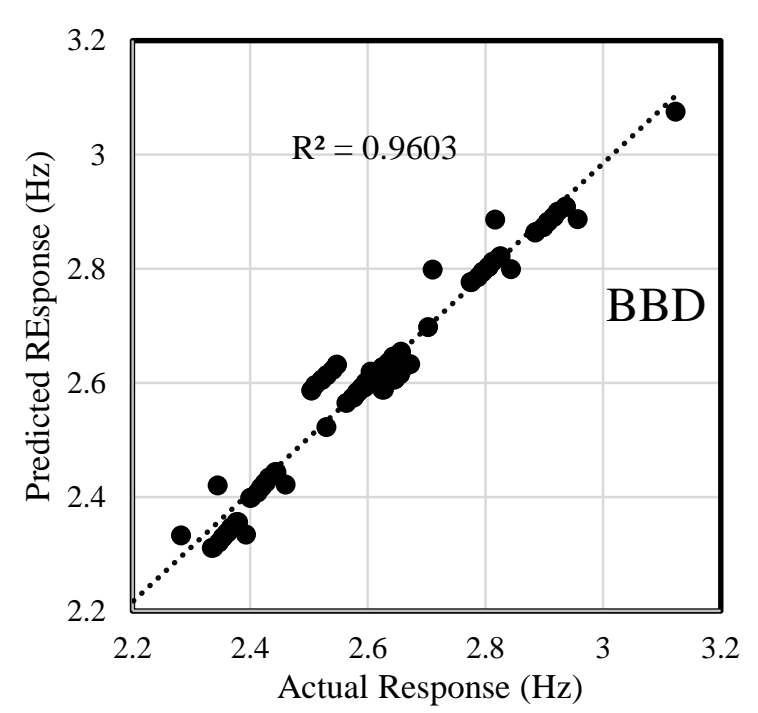

(b) BBD

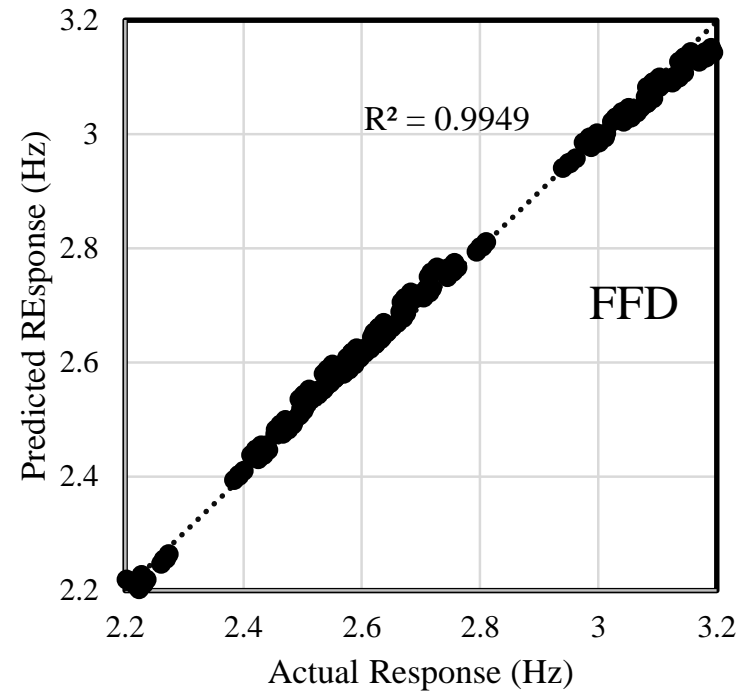

(a) FFD

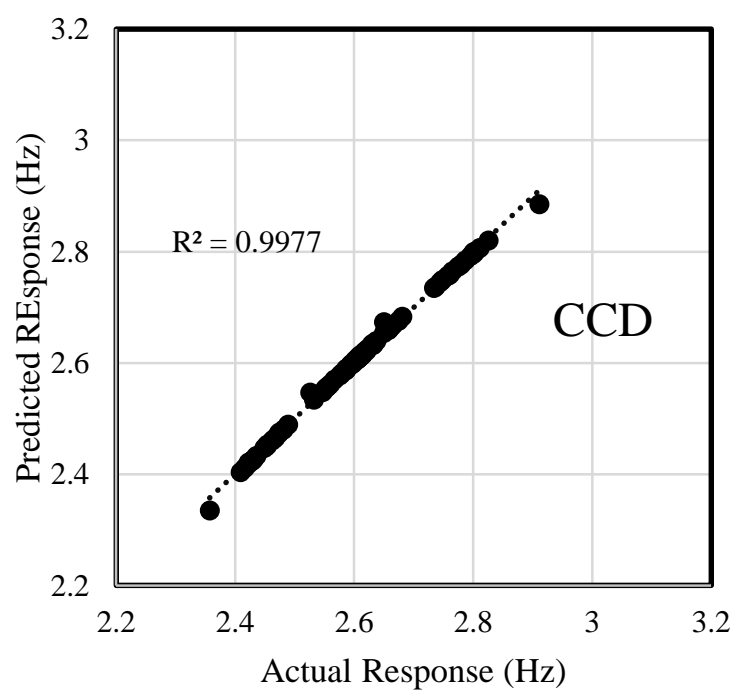

(c) CCD

Figure 4. Comparison of natural frequency with predicted values using RSM metamodels

\subsection{Comparison of the metamodels}

By using various non-statistical stochastic methods (BBD, CCD, FFD and HDMR), various metamodel formulation to determine the natural frequency of an asymmetric building subjected to randomness in various properties significant in affecting the said response was obtained. From Fig. 3 and Fig. 4 which compared the metamodel results with the actual response obtained from the finite element analysis (free vibration), it is observed that HDMR method shows the least (or no) variation between them; the reason mentioned above. The major efficacy of the metamodel 
approach is that, once formed, the user need not do further finite element procedures to determine the frequency of the system for another set of input variables. So the metamodel is suitable for structural designers in potential building construction and retrofitting areas, when they need to study the building frequency subjected to various changing properties.

To validate the accuracy of the metamodels formed, a comparison with Monte Carlo Simulation (MCS) was done. For this, 100000 combinations of the studied input variables $\left(E_{c}, w_{L}, h, B_{d}, B_{w}\right.$, $C_{d}, C_{w}$ and $e$ ) was generated using the same distribution as used before (Table 1). The finite element free vibration analyses of these input set was carried out to find the frequency corresponding to each input combination. Further, for the same set of 100000 input combinations, the metamodel frequency values for all the methods was found out, and compared with that of FE analysis. The results are shown in Fig. 5. As evident from the graphs, HDMR metamodel displays the most efficiency in calculating the frequency response of a system subjected to varying input parameters considered here. Table 6 summarizes the suitability of each of the metamodel approach by the number of sampling points, mean frequency and its standard deviation. HDMR, BBD and CCD methods were found to require less number of sampling points for finite elements analyses to formulate the metamodel as compared to FFD and MCS. Among all these, HDMR method requires the least number of FE analysis (17) with considerable accuracy of determining the frequency response. Thus proving the effectiveness of the HDMR method over other conventional methods.

A probabilistic distribution of natural frequency values obtained using the various metamodel approaches was plotted in Fig. 6. The statistical difference between the probability distributions of natural frequencies obtained by the various methods is negligible, and the frequencies are found to be normally distributed.

\section{Validation of the HDMR approach}

Until the previous section, the present investigation was successful in obtaining metamodels by various stochastic approaches to determine the uncoupled lateral frequency of a given set of mass asymmetric building subjected to randomness in its material, geometric and loading properties. The torsional frequency of the building can also be predicted similarly, and can be used to determine the uncoupled frequency ratio; which is a central parameter influencing the behaviour of asymmetric buildings. Among all the metamodels considered in the study, the High 
Dimensional Modal Representation approach was found to give the most accurate convergence of natural frequency with the least number of sampling points. But so far, the study was limited to the linear response of building structures. The behaviour of a building reaching the non-linear region is entirely different and could be more unpredictable. In this section, the efficiency of the HDMR approach in determining the nonlinear time history response of a building structure is investigated.

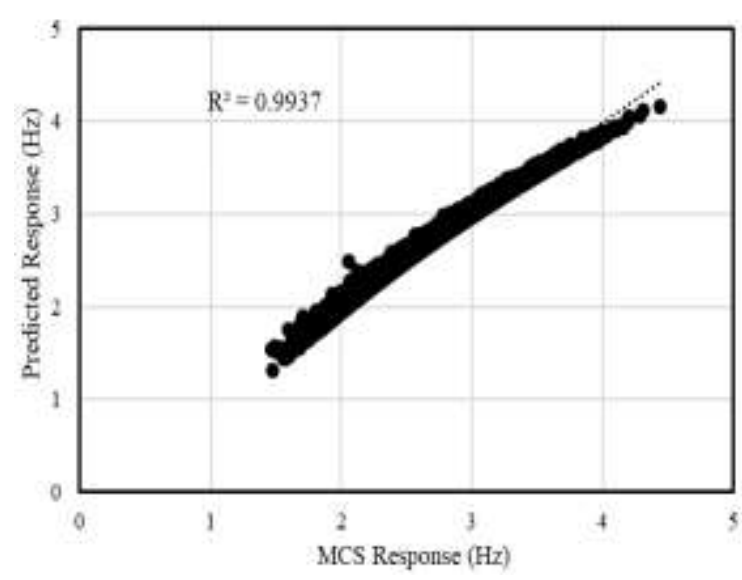

(a) HDMR

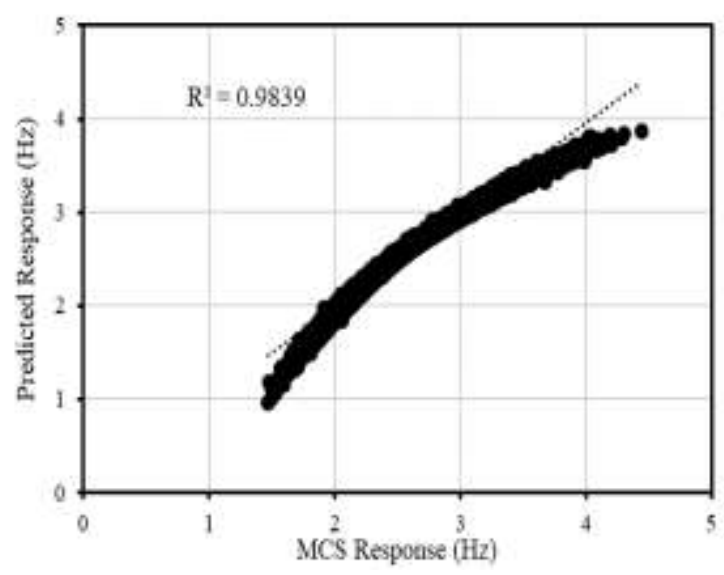

(c) FFD

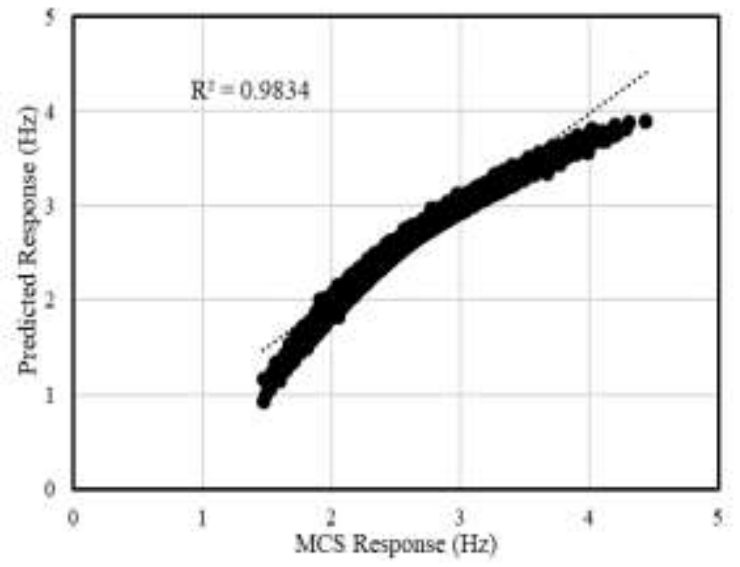

(a) BBD

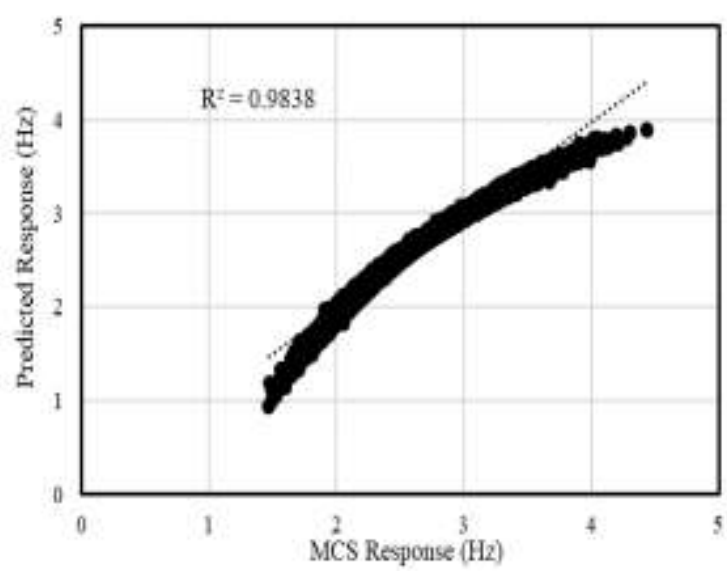

(d) $\mathrm{CCD}$

Figure 5. Comparison of metamodel responses with MCS responses

Table 6. Statistical parameters of natural frequency from different methods 


\begin{tabular}{|l|l|l|l|l|}
\hline Method & Mean (Hz) & Std. Dev. (Hz) & $\begin{array}{l}\text { Samples Required } \\
\text { for metamodel }\end{array}$ & $\begin{array}{l}\text { Number of } \\
\text { simulations }\end{array}$ \\
\hline HDMR & 2.627 & 0.337 & $17^{*}$ & 100000 \\
\hline CCD & 2.606 & 0.340 & $100^{*}$ & 100000 \\
\hline BBD & 2.609 & 0.339 & $120^{*}$ & 100000 \\
\hline FFD & 2.602 & 0.337 & $256^{*}$ & 100000 \\
\hline MCS & 2.621 & 0.339 & - & $100000^{\#}$ \\
\hline
\end{tabular}
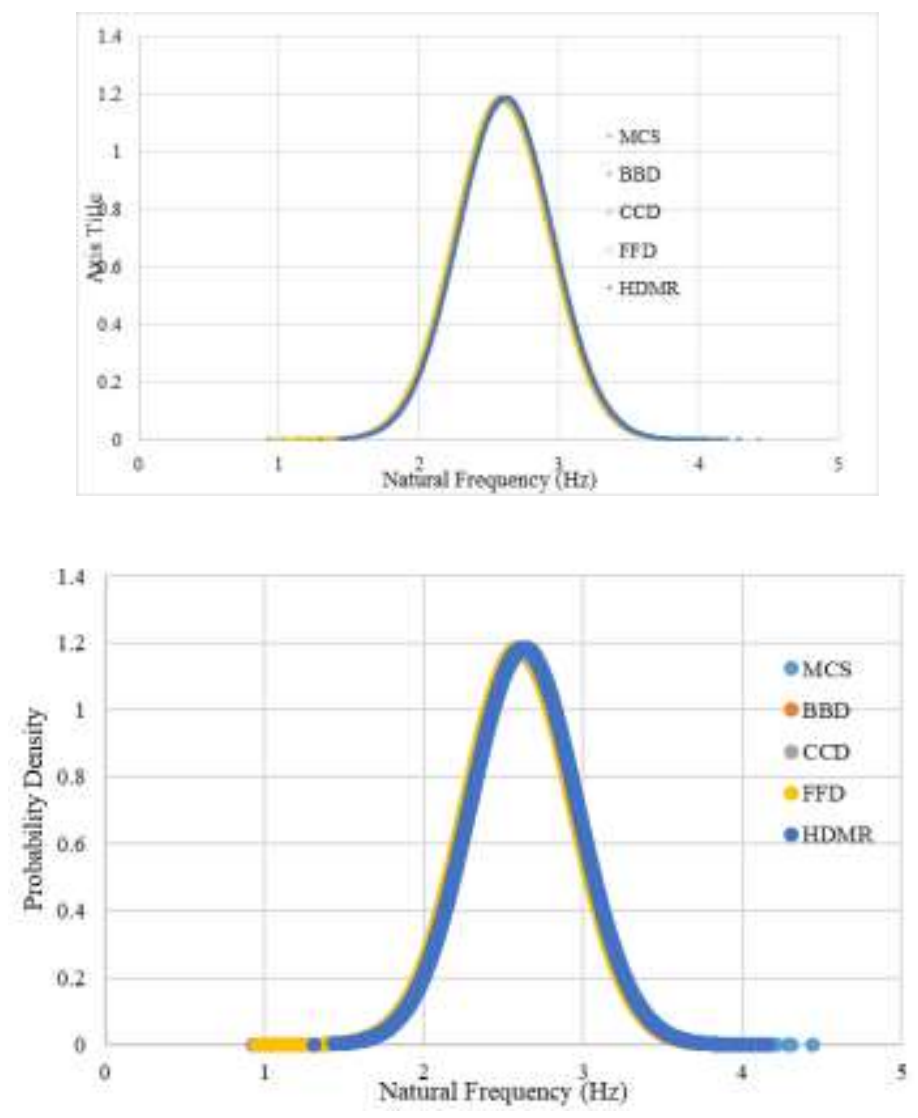

Figure 6. Probability distribution of natural frequency, obtained using various stochastic methods The same example building used for the linear study, whose geometric and section details are as specified in Fig. 2 is taken as the example building for the nonlinear study as well, whose seismic capacity is designed for the highest seismic zone (0.36 g PGA) as per the Indian Standards [32]. 
The asymmetry of the structure is fixed to be at an eccentricity equal to $30 \%$ of the building lateral dimension from the $\mathrm{CG}$ of each storey. Since the number of sampling points required are larger and the time taken for nonlinear analyses of 3 dimensional buildings is much higher as compared to linear, DOE such as BBD, CCD and FFD are deliberately avoided in this investigation.

\section{Seismic Fragility}

The seismic fragility of buildings is considered as the suitable parameter to determine the nonlinear time history behaviour. The fragility function represents the probability of exceedance of a selected Engineering Demand Parameter $(E D P)$ for a selected structural limit state $(L S)$ for a specific ground motion intensity measure $(I M)$. Fragility curves are useful tools for the estimation of probability of structural damage because of earthquakes as a function of ground motion indices or other design parameters. Development of fragility curves and the techniques depends upon the EDP, LS, and IM used according to the circumstances. Commonly used damage parameter is the maximum inter storey drift (ISD), which is the displacement between two storey levels of a building. Monte Carlo method is suitable in simulating the randomness in properties, but the computational level and time taken is so high that formulation of a metamodel such as HDMR in determining the ISD is found to be necessary alternative. Previous studies [10], [11], [16] have shown the dependency of metamodel methods for developing fragility curves.

For the present study, maximum ISD in the building is considered as the output response, upon which the HDMR metamodel is built.

\subsection{Uncertainties}

The major material parameters that affect the displacement of structural buildings are their concrete compressive strength $\left(f_{c}\right)$, steel yield strength $\left(f_{y}\right)$ and their damping ratio $(\zeta)$. The randomness in these parameters can significantly vary the motion of a building and thus they have been considered as the input variables for the ISD determination. As for the loading parameter, considering the varying number of earthquake data used to define uncertainty in loading, the Peak Ground Acceleration (PGA) is considered as the variable parameter affecting the response. The distribution of these parameters as obtained from literature is tabulated in Table 7. The PGA is considered as a uniform distribution varying from $0.1 \mathrm{~g}$ to $1 \mathrm{~g}$, where $\mathrm{g}$ is the acceleration due to gravity.

Table 7. Statistical Details of Random Variables used in the nonlinear study 


\begin{tabular}{|l|l|l|l|l|}
\hline Random variables & Mean & COV $(\%)$ & $\begin{array}{l}\text { Probability } \\
\text { distribution }\end{array}$ & Source \\
\hline $\begin{array}{l}\text { Concrete compressive } \\
\text { strength }\left(f_{c}\right)\end{array}$ & $33.66 \mathrm{MPa}$ & 21.0 & Normal & {$[33]$} \\
\hline Steel yield strength $\left(f_{y}\right)$ & $483.47 \mathrm{MPa}$ & 10.0 & Normal & {$[33]$} \\
\hline Global damping ratio $(\xi)$ & $5 \%$ & 76.0 & Lognormal & {$[34]$} \\
\hline
\end{tabular}

\subsection{Ground Motions Considered}

Randomness in ground motion is taken into account by using 44 scaled earthquake records. The ground motion data is taken from the work done by Haselton et al. [35]. They are modified and converted to match with design spectrum of Indian Standard IS 1893 (2016) [32] using a computer program WavGen, developed by Mukherjee and Gupta [36]. This program decomposes a recorded accelerogram into a finite number of time histories with energy in non-overlapping frequency bands and scales these time histories up/down iteratively such that the assembled time-history is compatible with a specified design spectrum. Details about the generation of synthetic accelerogram can found in [36]. These accelerograms are said to be synthetic accelerograms, which are later scaled linearly varying PGA from $0.1 \mathrm{~g}$ to $1 \mathrm{~g}$ for non-linear time history analysis.

\subsection{Metamodel formulation using HDMR}

Similar to the free vibration response considered in the previous sections, the metamodel for nonlinear analysis is also a polynomial functional relationship between the input variables and the output response. The only difference being that since nonlinear analysis is more random and unpredictable as compared to the linear one, two separate metamodels need to formed and combined; one at the mean and other at the standard deviation points to determine the maximum ISD response of the building. Utilizing Eq. (3) the metamodels for the two cases are defined for the current scenario as

$$
\begin{aligned}
& I S D_{\mu}=f_{0}+f\left(f_{c}\right)+f\left(f_{y}\right)+f(\xi)+f(P G A) \\
& I S D_{\sigma}=f_{0}+f\left(f_{c}\right)+f\left(f_{y}\right)+f(\xi)+f(P G A)
\end{aligned}
$$


Where the functions $f\left(f_{c}\right), f\left(f_{y}\right), f(\xi)$ in Eq. (11) and Eq. (12) form the same second order polynomial as in Eq. (8). The procedure follows the same format as before, i.e. to find out the coefficients $a_{0}, a_{1}$ and $a_{2}$ for each of the input variable considered so as to develop the metamodel, but this time for mean and standard deviation as well. For this, nonlinear analysis is carried out at the HDMR sampling points. Since there are 4 variables, the number of points comes out to be 9 $(4 * 2+1)$. Three-point sampling method as described in Fig. (1) is used here as well. The values for three-point sampling scheme for each of the 4 random variables are given in Table 8 and the 9 combination of the random variables are as shown in Table 9.

Table 8. Values of input variables obtained using three-point sampling

\begin{tabular}{|c|c|c|c|}
\hline Variable & $\mu-\sigma$ & $\mu$ & $\mu+\sigma$ \\
\hline$f_{c}(\mathrm{MPa})$ & 26.59 & 33.66 & 40.73 \\
\hline$f_{y}(\mathrm{MPa})$ & 435.13 & 483.48 & 531.82 \\
\hline$\xi(\%)$ & 1.2 & 5 & 8.8 \\
\hline$P G A(g)$ & 0.1 & 0.55 & 1 \\
\hline
\end{tabular}

Table 9. Set of input and output combinations in HDMR

\begin{tabular}{|c|c|c|c|c|c|c|}
\hline S1. No & $f_{c}(\mathrm{MPa}) 10^{6}$ & $f_{y}(\mathrm{MPa})$ & $\xi(\%)$ & $P G A(g)$ & $I S D_{\mu}$ & $I S D_{\sigma}$ \\
\hline 1 & 33.66 & 483.48 & 5.0 & 0.55 & 0.729656776 & 0.225727131 \\
\hline 2 & 40.73 & 483.48 & 5.0 & 0.55 & 0.670360176 & 0.199795312 \\
\hline 3 & 26.59 & 483.48 & 5.0 & 0.55 & 0.813675754 & 0.255581204 \\
\hline 4 & 33.66 & 531.82 & 5.0 & 0.55 & 0.730113138 & 0.225408478 \\
\hline 5 & 33.66 & 435.13 & 5.0 & 0.55 & 0.72280091 & 0.221245602 \\
\hline 6 & 33.66 & 483.48 & 1.2 & 0.55 & 1.04517483 & 0.326534074 \\
\hline
\end{tabular}




\begin{tabular}{|c|c|c|c|c|c|c|}
\hline 7 & 33.66 & 483.48 & 8.8 & 0.55 & 0.608753044 & 0.183353936 \\
\hline 8 & 33.66 & 483.48 & 5.0 & 1.00 & 1.422826089 & 0.439742353 \\
\hline 9 & 33.66 & 483.48 & 5.0 & 0.10 & 0.12236374 & 0.033863959 \\
\hline
\end{tabular}

Modeling and analysis of the building considered using the OpenSees framework at the 9 sampling points for each of the 44 earthquake data is carried out. From the data obtained on the displacements of the building, the mean () and standard deviation of the maximum ISD is determined. The nine equations at the nine sampling points are solved to obtain the unknown coefficients that define the metamodel.

Overall metamodel that represent the stochastic inter-storey drift response is expressed by combining the metamodels for mean and standard deviation of ISD as:

$$
I S D=I S D_{\mu}+N\left[0, I S D_{\sigma}\right]
$$

Where

$I S D$ - Maximum inter-storey drift obtained from the overall metamodel

$I S D_{\mu}$ - Metamodel representing mean of the inter-storey drift (Eq. 11)

$I S D_{\sigma}$ - Metamodel representing standard deviation of the inter-storey drift (Eq. 12)

$N\left[0, I S D_{\sigma}\right]$ - Normal probability distribution with mean zero and standard deviation, $I S D_{\sigma}$

Coefficients obtained for the metamodel are given in Table 10.

Table 10. Coefficients of metamodel for ISD obtained using HDMR approach

\begin{tabular}{|l|c|c|c|c|c|}
\hline \multicolumn{2}{|l|}{ Metamodel coefficients } & $f_{c}$ & $f_{y}$ & $\xi$ & $P G A$ \\
\hline \multirow{3}{*}{ Mean $\left(I S D_{\mu}\right)$} & $a_{0}$ & 0.621369 & -0.35654 & 0.455588 & - \\
& & & & & 0.730584834 \\
\cline { 2 - 6 } & $a_{1}$ & -0.02678 & 0.001399 & -12.4811 & 1.211713956 \\
\hline
\end{tabular}




\begin{tabular}{|l|c|c|c|c|c|}
\hline & $a_{3}$ & 0.000247 & $-1.4 \mathrm{E}-06$ & 67.38723 & 0.21204019 \\
\hline \multirow{3}{*}{ Standard deviation $(I S D \sigma)$} & $a_{0}$ & 0.177239 & -0.26083 & 0.144781 & $\begin{array}{c}- \\
0.231491129\end{array}$ \\
\cline { 2 - 6 } & $a_{1}$ & -0.00658 & 0.001036 & -3.90728 & 0.390809932 \\
\cline { 2 - 6 } & $a_{3}$ & $3.92 \mathrm{E}-05$ & $-1 \mathrm{E}-06$ & 20.23329 & 0.05469642 \\
\hline
\end{tabular}

Fig. 7 shows the graph between the maximum ISD from the nonlinear time history analyses and the maximum ISD value using the metamodel formed using Eq. (13) and Table 10. There is no error $\left(R^{2}=1\right)$ between both the values, denoting the accuracy of the HDMR coefficients. Because of the hectic computational effort and time consumption, comparison with MCS output is omitted here. Instead fragility curves are generated using HDMR metamodel with MCS sampling points and compared with the fragility obtained using conventional methods with Latin Hypercube Sampling (LHS). It can be assumed with good approximation, from Figs. 3 and 4, that the metamodel formed using other DOE will predict the maximum ISD with less accuracy than HDMR.

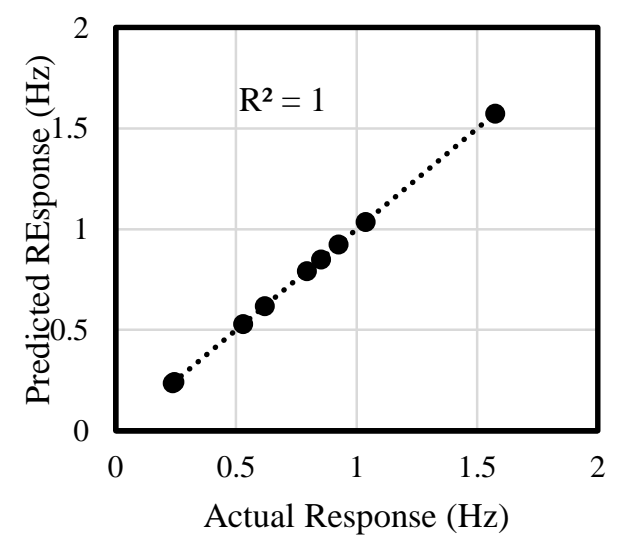

Figure 7. Comparison of ISD at sampling points and predicted ISD using HDMR metamodel

\subsection{Generating Fragility Curves using HDMR}

Fragility curve is plotted between the probability of failure of the damage parameter and the intensity measure with respect to a well-defined limit state or performance level. For the present study, maximum ISD is considered as the EDP and the PGA is considered as the IM. So basically 
for a given pga, the fragility curve reads the exceedance probability of the structural failure when it exceeds the building standards. The damage limit states corresponding to various performance levels required for the fragility analysis of the example asymmetric building frame is taken from [37]. Table 11 summarizes the ISD (\%) at the performance limit states, Immediate Occupancy (IO), Life Safety (LS) and Collapse Prevention (CP).

Table 11. Maximum ISD Limit States

\begin{tabular}{|l|l|}
\hline Performance level & ISD (\%) \\
\hline Immediate Occupancy (IO) & $1 \%$ \\
\hline Life Safety (LS) & $2 \%$ \\
\hline Collapse Prevention (CP) & $4 \%$ \\
\hline
\end{tabular}

To build the fragility curve using HDMR method, 100000 combinations of the input variables $\left(f_{c}, f_{y}, \xi\right)$ are generated using MCS by considering their distribution as given in Table 8 . For each value of PGA from $0.1 \mathrm{~g}-4 \mathrm{~g}, 100000$ ISD values are generated using the HDMR metamodel as given in Eq. (13). The probability of exceedance of these values with each limit state is calculated and the probability value for each corresponding PGA is plotted to form the fragility curves as shown in Fig 8.

\subsection{Comparison of fragility curves}

To observe the efficiency of the HDMR method in nonlinear spectrum, fragility curve plotted using the HDMR metamodel (Fig. 8) is compared with the curve obtained using conventional methods. Fragility function proposed by Cornell et al [38] is generally considered in this regard, which uses a lognormal assumption to develop the fragility curves of RC structures using closed form equation as given

$$
P(D \geq C \mid I M)=1-\phi\left(\frac{\ln \frac{S_{C}}{S_{D}}}{\sqrt{\beta_{D \mid M}^{2}+\beta_{c}^{2}+\beta_{M}^{2}}}\right)
$$


where, $D$ is the drift demand, $C$ is the drift capacity at chosen limit state, $S_{C}$ and $S_{D}$ are the chosen limit state and the median of the demand $(L S)$ respectively. $\beta_{d / I M}, \beta_{c}$ and $\beta_{M}$ are dispersions in the intensity measure, capacities and modelling respectively.

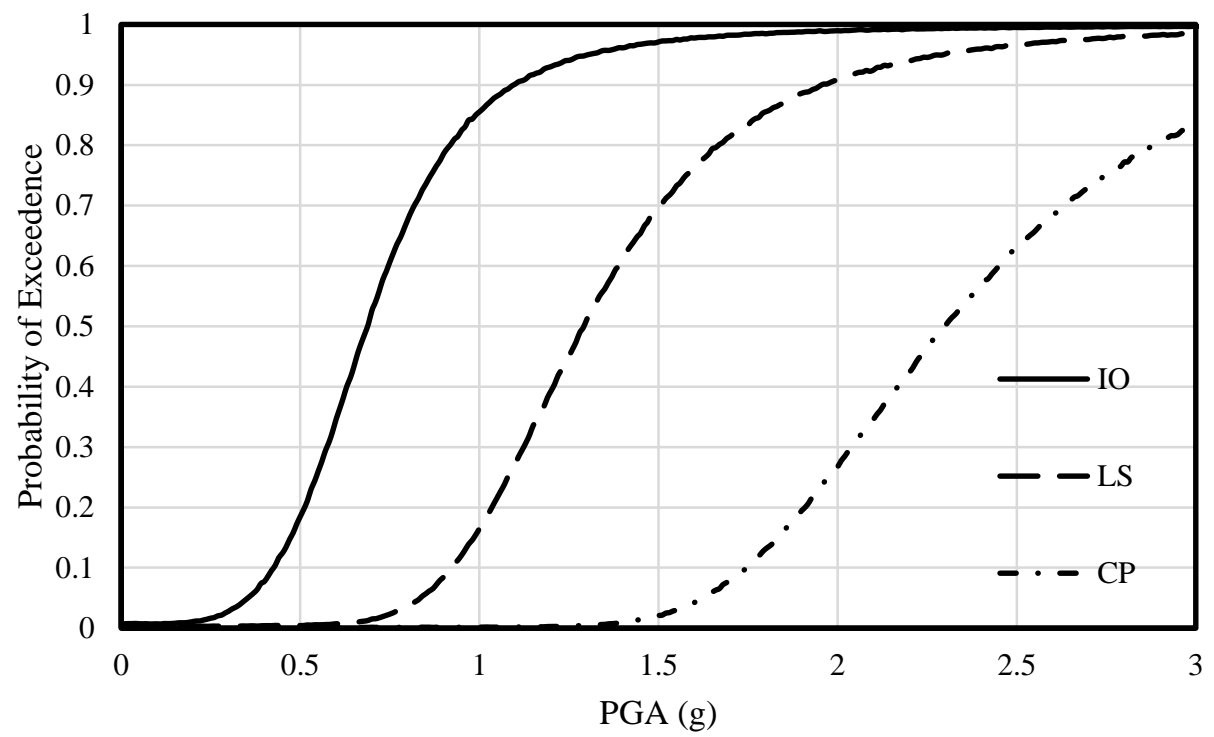

Figure 8. Fragility Curves using HDMR

Latin Hypercube Sampling technique is used to sample the random variables into 44 different sampling points, corresponding to every Earthquake considered. The PGA values are uniformly distributed between $0.1 \mathrm{~g}$ and $1 \mathrm{~g}$. Non-linear time history analysis is carried out in the asymmetric building considered and the maximum ISD values were obtained, from which the fragility curve is obtained using Eq, (14). Figs 9-11 compares the fragility curves obtained using HDMR metamodel and Cornell's method for the three limit states. 


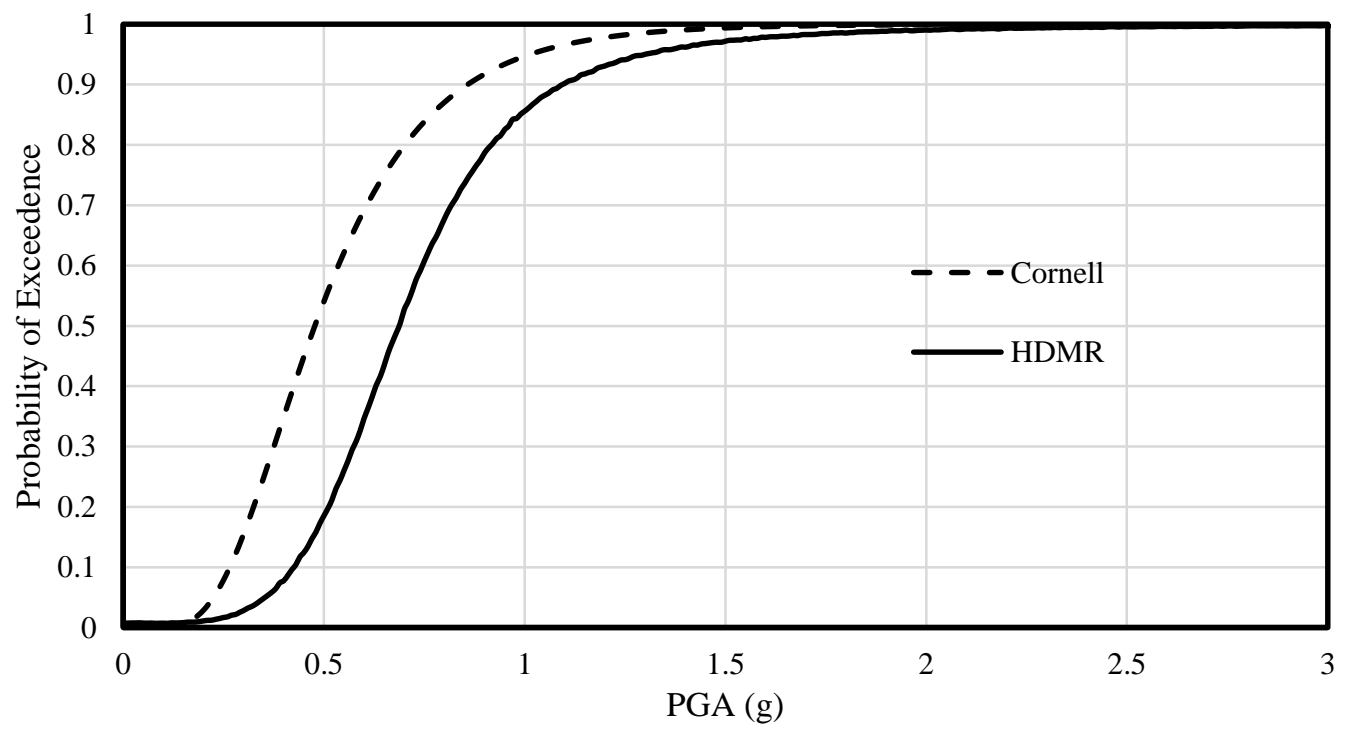

Figure 9. Comparison of fragility curves for IO limit state

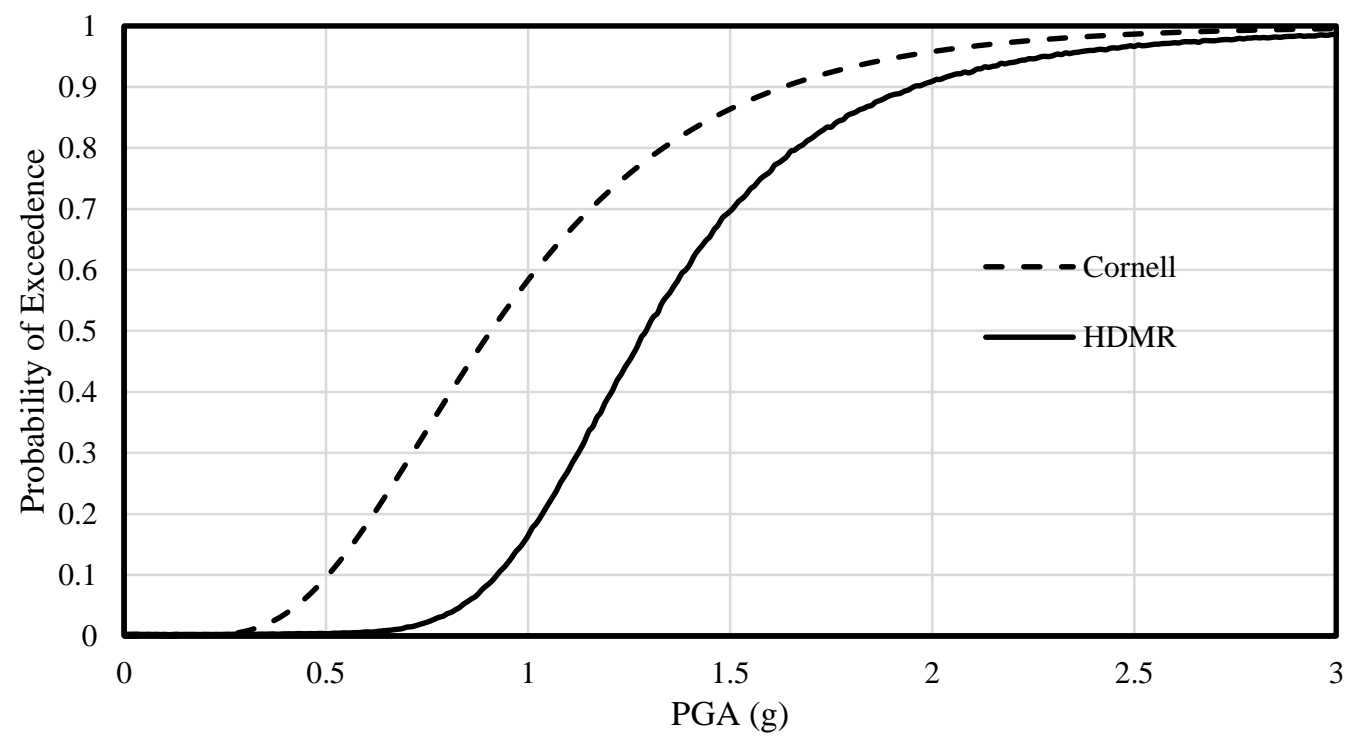

Figure 10. Comparison of fragility curves for LS limit state 


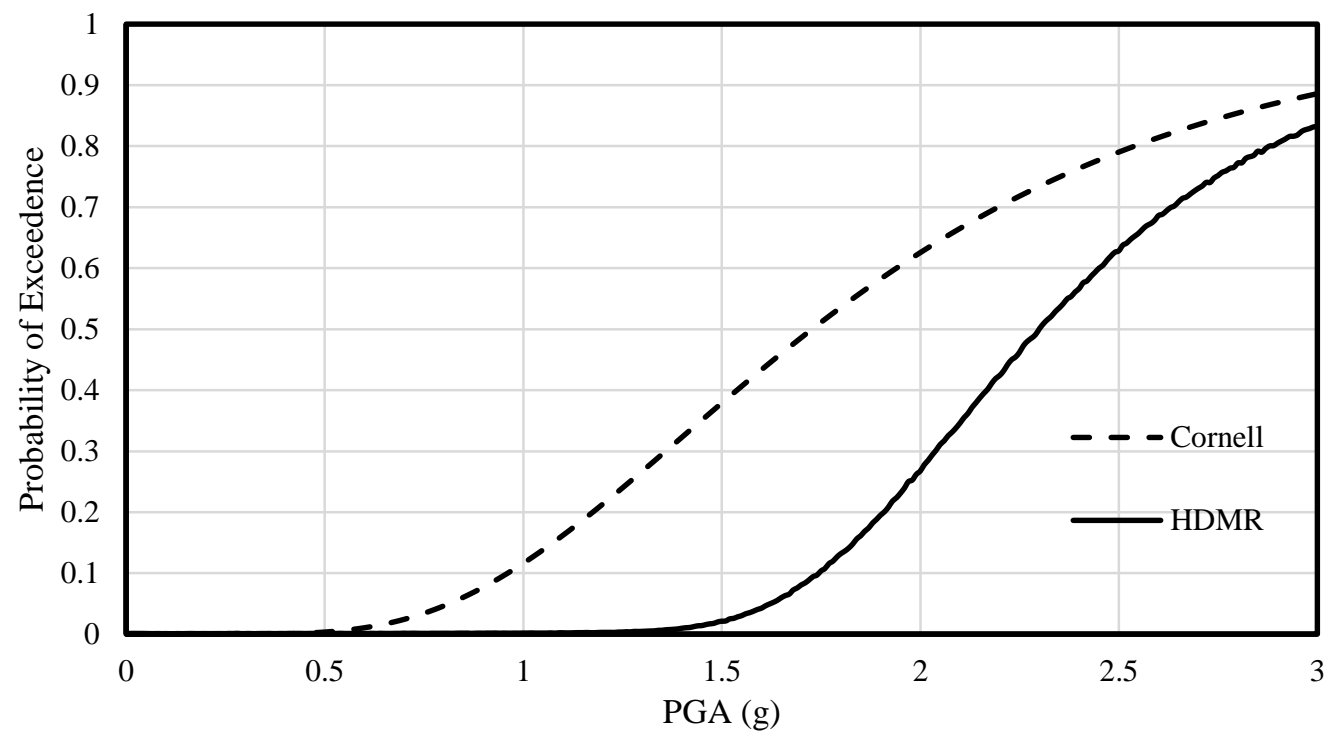

Figure 11. Comparison of Fragility Curves for CP limit state

\section{Conclusion}

Asymmetry in plan that occurs due to the non-co-incident nature of CM and CS can caused torsional-lateral coupled motion in building structures, which make them further vulnerable to dynamic loads such as Earthquakes, Tsunamis etc... In addition to this, certain material, geometric and loading parameters of the building could deviate from the designed values, causing randomness in these properties; which further affects the building behaviour. So a method that can properly quantify these uncertainties is desired for. Stochastic methods of analyses are usually done as to this regard, but the most commonly followed statistical approaches such as MCS, LHS etc... are computationally cumbersome as well as expensive. The present study considers the various non-statistical methods of stochastic analyses, the metamodel approach. This involves formulation of a metamodel, which is basically an input-output relationship, relating between the uncertain parameters and the desired response of the building.

Metamodels were formulated for known approaches such as BBD, CCD, FFD and HDMR as to obtain the natural frequency of an asymmetric building subjected to randomness in various parameters. Investigations using free vibration analysis concluded the effectiveness of the HDMR over other approaches in accurately predicting the natural frequency of the building with the least number of sampling points required to obtain the metamodel. To verify the effect of HDMR 
method over the nonlinear region, time history analyses was conducted at HDMR sampling points to derive the maximum ISD metamodel for the building. Using this fragility curves were generated, which was found to be in accordance with the curves generated using conventional methods.

The metamodels obtained in the study is only specific to the set of asymmetric building having certain similarity in characteristics, especially their geometry. An altogether different metamodel set need to be obtained for frames having another set of values for number of stories or number of bays. However, the methodology is applicable and relevant to other structures also. Future studies

should aim at buildings having vertical eccentricity, shear walls, bracings or steel sections and randomness in their corresponding parameters.

\section{References}

[1] J. Xu, J. Chen, and J. Li, "Probability density evolution analysis of engineering structures via cubature points," Comput. Mech., vol. 50, no. 1, pp. 135-156, 2012.

[2] S. Chakraborty, B. Mandal, R. Chowdhury, and A. Chakrabarti, "Stochastic free vibration analysis of laminated composite plates using polynomial correlated function expansion," Compos. Struct., vol. 135, pp. 236-249, 2016.

[3] D. P. Kroese and R. Y. Rubinstein, SIMULATION AND THE MONTE CARLO METHOD. 2017.

[4] M. Stein, "Large Sample Properties of Simulations Using Latin Hypercube Sampling," Technometrics, vol. 29, no. January 2014, pp. 37-41, 2012.

[5] W. A. Ericson, “Optimum Stratified Sampling Using Prior Information,” J. Am. Stat. Assoc., 2012.

[6] J. B. Cardoso, J. R. de Almeida, J. M. Dias, and P. G. Coelho, "Structural reliability analysis using Monte Carlo simulation and neural networks," Adv. Eng. Softw., vol. 39, no. 6 , pp. 505-513, 2008.

[7] G. E. P. Box and K. B. Wilson, "On the Experimental Attainment of Optimum Conditions," vol. I, no. 1959, pp. 270-310, 1992.

[8] G. E. P. Box and D. W. Behnken, "Some New Three Level Designs for the Study of 
Quantitative Variables," Technometrics, vol. 2, no. 4, pp. 455-475, 1960.

[9] P. Franchin, A. Lupoi, P. E. Pinto, And M. I. Schotanus, "Seismic Fragility Of Reinforced Concrete Structures Using A Response Surface Approach," J. Earthq. Eng., vol. 7, no. sup001, pp. 45-77, 2003.

[10] J. Seo and D. G. Linzell, "Use of response surface metamodels to generate system level fragilities for existing curved steel bridges," Eng. Struct., vol. 52, pp. 642-653, 2013.

[11] J. Seo, L. Dueñas-Osorio, J. I. Craig, and B. J. Goodno, "Metamodel-based regional vulnerability estimate of irregular steel moment-frame structures subjected to earthquake events,” Eng. Struct., vol. 45, pp. 585-597, 2012.

[12] J. Park and P. Towashiraporn, "Rapid seismic damage assessment of railway bridges using the response-surface statistical model," Struct. Saf., vol. 47, pp. 1-12, 2014.

[13] N. Buratti, B. Ferracuti, and M. Savoia, "Response Surface with random factors for seismic fragility of reinforced concrete frames," Struct. Saf., vol. 32, no. 1, pp. 42-51, 2010.

[14] H. Rabitz, Ö. F. Aliş, J. Shorter, and K. Shim, "Efficient input-output model representations," Comput. Phys. Commun., vol. 117, no. 1, pp. 11-20, 1999.

[15] A. Brault, L. Dumas, and D. Lucor, "Uncertainty quantification of inflow boundary condition and proximal arterial stiffness coupled effect on pulse wave propagation in a vascular network," no. April 2008, pp. 301-337, 2016.

[16] V. U. Unnikrishnan, A. M. Prasad, and B. N. Rao, "Development of fragility curves using high-dimensional model representation," no. June 2012, pp. 419-430, 2014.

[17] P. Towashiraporn and P. Gardoni, "Building Seismic Fragilities Using Response Surface Metamodels," Civil and Environmental Engineering, vol. Doctor of, no. August. p. 237, 2004.

[18] H. Rushing, A. Karl, and J. Wisnowski, "Design and Analysis of Experiments," Des. Anal. Exp. by Douglas Montgomery A Suppl. Using JMP, pp. 101-128, 2013.

[19] S. Annigeri, A. K. Mittal, and A. K. Jain, "Uncoupled frequency ratio in asymmetric 
buildings," Earthq. Eng. Struct. Dyn., vol. 25, no. 8, pp. 871-881, 1996.

[20] W. K. Tso and K. M. Dempsey, "Seismic torsional provisions for dynamic eccentricity," Earthq. Eng. Struct. Dyn., vol. 8, no. 3, pp. 275-289, 1980.

[21] R. Hejal and A. K. Chopra, "Lateral-Torsional Coupling in Earthquake Response of Frame Buildings," J. Struct. Eng., vol. 115, no. 4, pp. 852-867, 1989.

[22] C. G. Stathi, N. P. Bakas, N. D. Lagaros, and M. Papadrakakis, "Ratio of Torsion (ROT): An index for assessing the global induced torsion in plan irregular buildings," Earthq. Struct., vol. 9, no. 1, pp. 145-171, 2015.

[23] Bureau of Indian Standard(BIS), "Plain and Reinforced Concrete - Code of Practice," IS 456(4th rev.), no. July, 2000.

[24] F. McKenna, M. H. Scott, and G. L. Fenves, "Nonlinear Finite-Element Analysis Software Architecture Using Object Composition,” J. Comput. Civ. Eng., vol. 24, no. 1, pp. 95-107, 2010.

[25] T. H. Lee and K. M. Mosalam, "Probabilistic fiber element modeling of reinforced concrete structures," Comput. Struct., vol. 82, no. 27, pp. 2285-2299, 2004.

[26] D. C. Kent and R. Park, "Flexural Members with Confined Concrete," J. Struct. Div., vol. 97, no. 7, pp. 1969-1990, 1971.

[27] F. C. Filippou, E. P. Popov, and V. V. Bertero, "Effects of Bond Deterioration on Hysteretic Behaviour of Reinforced Concrete Joints. Report to the National Science Foundation," Earthq. Eng. Res. Cent., no. August, pp. 1-212, 1983.

[28] C. C. Mitropoulou, N. D. Lagaros, and M. Papadrakakis, "Life-cycle cost assessment of optimally designed reinforced concrete buildings under seismic actions," Reliab. Eng. Syst. Saf., vol. 96, no. 10, pp. 1311-1331, 2011.

[29] B. Ö. Ay, "Fragility Based Assessment of Low-Rise and Mid-Rise Reinforcement Concrete Frame Buildings in Turkey," 2006.

[30] I. E. Bal, H. Crowley, R. Pinho, and F. G. Gülay, "Detailed assessment of structural characteristics of Turkish RC building stock for loss assessment models," Soil Dyn. 
Earthq. Eng., vol. 28, no. 10-11, pp. 914-932, 2008.

[31] D. Val, F. Bljuger, and D. Yankelevsky, "Reliability evaluation in nonlinear analysis of reinforced concrete structures," Struct. Saf., vol. 19, no. 2, pp. 203-217, 1997.

[32] Bureau of Indian Standard(BIS), "Criteria for Earthquake Resistant Design of Structures," IS 1893 (Part 1) 2016, no. December, 2016.

[33] R. Ranganathan, Reliability Analysis and Design of Structure. Tata McGraw-Hill, 1990.

[34] O. C. Celik and B. R. Ellingwood, "Seismic fragilities for non-ductile reinforced concrete frames - Role of aleatoric and epistemic uncertainties," Struct. Saf., vol. 32, no. 1, pp. 1$12,2010$.

[35] C. B. Haselton, A. S. Whittaker, A. Hortacsu, J. W. Baker, J. D. Bray, and D. N. Grant, "Selecting and Scaling Earthquake Ground Motions for Performing Analyses," 15th World Conf. Earthq. Eng., pp. 1-256, 2012.

[36] S. Mukherjee and V. K. Gupta, "Wavelet-based generation of spectrum-compatible timehistories," Soil Dyn. Earthq. Eng., vol. 22, no. 9-12, pp. 799-804, 2002.

[37] FEMA, "Prestandard and Commentary for the Seismic Rehabilitation of Buildings," Rehabil. Requir., no. 1, pp. 1-518, 2000.

[38] C. A. Cornell, F. Jalayer, R. O. Hamburger, and D. A. Foutch, "Probabilistic Basis for 2000 SAC Federal Emergency Management Agency Steel Moment Frame Guidelines," J. Struct. Eng., vol. 128, no. April 2002, pp. 526-533, 2002. 